Check for updates

Cite this: Phys. Chem. Chem. Phys., 2020, 22, 11713

Received 19th March 2020, Accepted 5th May 2020

DOI: $10.1039 / \mathrm{d} 0 \mathrm{cp} 01506 \mathrm{~g}$

rsc.li/pccp

\title{
Structural dynamics of an iron molybdate catalyst under redox cycling conditions studied with in situ multi edge XAS and XRD $\dagger$
}

\author{
Abhijeet Gaur, (D) *ab Matthias Stehle, (D) ${ }^{a}$ Kristian Viegaard Raun, ${ }^{c}$ \\ Joachim Thrane, (D) ${ }^{c}$ Anker Degn Jensen, (D) ${ }^{c}$ Jan-Dierk Grunwaldt (iD) ${ }^{\text {ab }}$ and \\ Martin $\mathrm{H} \varnothing \mathrm{j}\left(\mathbb{D} *{ }^{*}\right.$
}

\begin{abstract}
The structural dynamics and phase transformations of an iron molybdate catalyst with excess molybdenum trioxide $(\mathrm{Mo} / \mathrm{Fe}=2.0)$ were studied during redox cycling of the catalyst using in situ multiedge X-ray absorption spectroscopy (XAS) at the Mo K-edge (transmission mode) and Fe K-edge (fluorescence mode) in combination with X-ray diffraction (XRD). X-ray absorption near edge structure (XANES) and extended X-ray absorption fine structure (EXAFS) analysis showed that heating under reducing conditions with methanol up to $400{ }^{\circ} \mathrm{C}$ produced $\mathrm{MoO}_{2}$ and $\mathrm{FeMoO}_{4}$. Linear combination fitting (LCF) analysis showed that iron was reduced completely, while molybdenum remained partly oxidized $(60 \%$ as $\mathrm{Mo}(\mathrm{VI}))$. Complementary in situ XRD also supported the phase transformation due to reduction of $\mathrm{Fe}_{2}\left(\mathrm{MoO}_{4}\right)_{3}$ and $\mathrm{MoO}_{3}$ to $\mathrm{FeMOO}_{4}$ and $\mathrm{MoO}_{2}$. Subsequent heating under oxidative conditions from 200 to $500{ }^{\circ} \mathrm{C}$ transformed the catalyst into its initial state via $\mathrm{Fe}_{2} \mathrm{O}_{3}$ and extra $\mathrm{MoO}_{3}$ as intermediate phases. This underlines the segregation and iron enrichment during redox cycling. $\mathrm{MoO}_{3}$ volatilization, observed under industrial reaction conditions of a methanol and oxygen containing atmosphere, causes this segregation to be permanent. Complete regeneration could only be achieved at $500{ }^{\circ} \mathrm{C}$, which is significantly higher than industrial reaction temperatures. Overall, multi edge in situ XAS along with complementary XRD was found to be an ideal tool for tracing the different amorphous and crystalline phases present during redox cycling of the catalyst.
\end{abstract}

\section{Introduction}

Iron molybdate with an excess of molybdenum oxide (denoted FeMo throughout the paper) is an industrially important

\footnotetext{
${ }^{a}$ Institute for Chemical Technology and Polymer Chemistry, Karlsruhe Institute of Technology (KIT), Karlsruhe, D-76131, Germany. E-mail: abhijeet.gaur@kit.edu; Tel: +4972160844320

${ }^{b}$ Institute of Catalysis Research and Technology, Karlsruhe Institute of Technology (KIT), Karlsruhe, D-76131, Germany

${ }^{c}$ Department of Chemical and Biochemical Engineering, Technical University of Denmark (DTU), Kgs. Lyngby, DK-2800, Denmark.E-mail: mh@kt.dtu.dk; Tel: +4545252842

$\dagger$ Electronic supplementary information (ESI) available: Overview of the experimental procedure, XANES spectrum of the initial state of the FeMo catalyst and the structural parameters obtained from EXAFS fitting, EXAFS fitting curves at the Mo K-edge for the FeMo catalyst during different stages of redox cycling, structural parameters obtained from EXAFS fitting for intermediate phases during TPR and TPO, PCA and LCF results at the Fe K-edge during TPR, MS traces of $\mathrm{MeOH}, \mathrm{HCHO}$ and $\mathrm{H}_{2} \mathrm{O}$ during TPR and isothermal period, in situ XANES spectra at the Mo K- and Fe K-edge and XRD during cooling down to $200{ }^{\circ} \mathrm{C}$ after TPR and switching to oxidizing conditions, complete LCF results at the Mo K-edge during TPO and PCA results at the Fe K-edge during TPO. See DOI: 10.1039/d0cp01506g
}

catalyst for the selective oxidation of methanol to formaldehyde, which has led to a number of fundamental studies concerning its structure, activity, mechanism, stability and deactivation. ${ }^{1-6}$ To improve the performance of a catalyst on a knowledge-based approach, it is critical to understand the structure and structural dynamics of the catalyst under reaction conditions. Commercial iron molybdate catalysts are typically formulated with an excess of molybdenum(vi)oxide, since Mo is known to volatilize from the reactor inlet and hot $\operatorname{spot}^{7}$ during the reaction, leaving an unselective Fe rich surface. ${ }^{8}$ The FeMo system contains multiple distinct phases including bulk $\alpha$ $\mathrm{MoO}_{3}$ and $\mathrm{Fe}_{2}\left(\mathrm{MoO}_{4}\right)_{3}$, as well as a surface layer of $\mathrm{MoO}_{x}$ on the $\mathrm{Fe}_{2}\left(\mathrm{MoO}_{4}\right)_{3}$ surface. ${ }^{9}$ Hence, it is difficult to assess the nature of the active sites and role of $\mathrm{Fe}_{2}\left(\mathrm{MoO}_{4}\right)_{3}$, specifically whether it merely acts as a support for the active $\mathrm{MoO}_{x}$ or whether it has its own inherent activity. The catalytic behavior of FeMo catalysts was observed to be mainly dependent on their $\mathrm{Mo} / \mathrm{Fe}$ atomic ratio. ${ }^{2,10}$ The most active phase composition of the bulk iron molybdate catalyst was proposed to have the stoichiometric $\mathrm{Mo} / \mathrm{Fe}$ ratio of $1.5^{3}$ and the function of excess $\mathrm{MoO}_{3}$ is speculated to maintain the active phase of the catalyst 
at this ratio. The activity and selectivity of bulk iron molybdate catalysts for methanol oxidation was examined as a function of $\mathrm{Mo} / \mathrm{Fe}$ ratios from 0.02 to $4,{ }^{2}$ revealing that $\mathrm{Mo} / \mathrm{Fe}$ ratios greater than 1.5 are required for high catalytic activity and selectivity to formaldehyde. The presence of an octahedral Mo oxide overlayer has been reported, ${ }^{1}$ which corresponds to one monolayer. Various groups have proposed that this overlayer structure is the fundamental, active surface for the selective oxidation of methanol to formaldehyde. ${ }^{1,9,11}$ The presence of two terminal oxygen atoms double bonded to Mo in such coordination allows the reacting methanol molecules to be bonded simultaneously at two points to the surface. The formation of several molybdenum oxy-methoxy compounds was also reported ${ }^{12}$ and it was argued that hydrogen abstraction of the methanol hydroxyl group produces methoxy species that are intermediates in formaldehyde formation. The role of $\mathrm{Fe}$ in iron molybdate catalysts would be to favor the transfer of $\mathrm{O}_{2}$ and $\mathrm{H}_{2} \mathrm{O}$ between the surface and the gas phase and to facilitate re-oxidation of reduced Mo. ${ }^{11}$ Furthermore, oxygen atoms from terminal $\mathrm{Mo}=\mathrm{O}$ groups were argued to be crucial for the activity and selectivity of $\mathrm{MoO}_{3} \cdot{ }^{13-16}$ Several samples revealed a co-existence of various $\mathrm{MoO}_{x}$ phases and similar qualitative phase compositions existed for different $\mathrm{Mo} / \mathrm{Fe}$ ratios which does not allow to draw any conclusions about a correlation between a certain $\mathrm{MoO}_{3}$ phase and its catalytic behavior.

In order to predict and model the performance of catalysts, their electronic and structural properties need to be studied at an atomic scale as they strongly influence the catalytic properties. Under dynamic conditions (temperature, pressure, gas atmosphere, etc.) catalysts can be chemically transformed, giving rise to changes in their initial surface composition correlated to bulk structure, morphology and particle size. Thus, complementary techniques have been used for detailed studies of the structural, electronic and chemical properties of different types of catalysts under these conditions. The combination of X-ray absorption spectroscopy (XAS) with complementary techniques can provide in situ and operando chemical, structural, and electronic insights into the catalysts and other involved species to holistically understand the catalytic process. XAS coupled with X-ray diffraction (XRD) is beneficial since the nature of crystallite phases can be determined by XRD whereas XAS is useful for determining the oxidation state and coordination geometry of the metal atoms. In order to evaluate the potential of the multiple-technique approach and usefulness of different in situ/operando reactors at the synchrotron facilities, the behavior of an $\mathrm{Fe}_{2}\left(\mathrm{MoO}_{4}\right)_{3}$ catalyst under redox conditions was discussed in the literature. ${ }^{17-19}$ During reduction in $\mathrm{MeOH}$, due to continuous removal of oxygen, pseudo-molybdate and a MoC type phase were observed, leading to the breakdown of the catalyst to separate oxides (low $\mathrm{Mo} / \mathrm{Fe}$ ratio of 1.5). ${ }^{17}$ The rate of re-oxidation was found to increase with increasing Mo concentration. Along with other observations, this clarified the role of $\mathrm{MoO}_{3}$ excess in the as-prepared catalyst, which is to maintain the stability of the active phase and to replenish any evaporated molybdenum. ${ }^{18}$

In a recent study ${ }^{20}$ on the same catalytic system, we have shown that during its evolution with time on stream for selective oxidation of methanol to formaldehyde, the FeMo catalyst undergoes strong structural changes due to evaporation of $\mathrm{MoO}_{3}$. In this study we now probe the structural changes of Mo and Fe related crystalline and amorphous phases during redox cycling using in situ multi-edge XAS at the Mo K- and Fe K-edges combined with complementary XRD. Using redox cycling in methanol and under oxidizing conditions insight into the structural dynamics can be received. The combination of multi-edge XAS and XRD allows for investigating the effect of over-reduction followed by re-oxidation of the catalyst, corresponding to one cycle of the selective oxidation of methanol to formaldehyde. For this purpose we exploited the advanced beamline set-ups available at the synchrotron radiation sources which allow obtaining high quality bulk structural data by XAS and XRD from catalysts under dynamic conditions when simultaneously using multiple techniques.

\section{Experimental}

The catalyst was prepared by hydrothermal synthesis with special interest paid to the precise adjustment of the atomic molybdenum to iron ratio. ${ }^{7}$ The $\mathrm{Mo} / \mathrm{Fe}$ ratio was 2.0 , which resulted in an active and selective catalyst in a broad temperature range, typically $250-400{ }^{\circ} \mathrm{C}$, at a feed concentration of 5 vol\% $\mathrm{CH}_{3} \mathrm{OH}$ with about 10 vol\% $\mathrm{O}_{2}{ }^{7}$ The catalyst was calcined at $535{ }^{\circ} \mathrm{C}$ in air, resulting in a BET surface area of $4.7 \mathrm{~m}^{2} \mathrm{~g}^{-1}$ and Rietveld refined particles size of $133 \mathrm{~nm}$ for the $\mathrm{MoO}_{3}$ phase and $375 \mathrm{~nm}$ for the $\mathrm{Fe}_{2}\left(\mathrm{MoO}_{4}\right)_{3}$ phase. The catalyst was crushed and ground with silica in a $1 / 5$ catalyst/silica weight ratio. This mixture was pressed as a pellet, crushed and sieved to $100-150 \mu \mathrm{m}$. Combined XAS/XRD studies during temperature programmed experiments were conducted at the SNBL beamline BM31 at ESRF, Grenoble, France. ${ }^{21}$ Fig. 1 shows the schematics of the advance experimental setup used for the in situ multi-edge XAS/XRD experiments. As optics requirements for high quality XAS and XRD are quite different, the beamline is equipped with a channel-cut monochromator (CCM) for a high-resolution powder diffraction and a second double crystal monochromator (DCM) for XAS (interchanged within $10 \mathrm{~s}$ ). ${ }^{21}$ Measurements were performed by means of a fixed-bed microreactor based on quartz glass capillaries ${ }^{22}$ for mimicking optimal heat and mass transfer. ${ }^{23,24}$ The catalyst in the form of powder was loaded in a glass capillary with inner diameter of $1.5 \mathrm{~mm}$ with the total bed length inside the capillary of $1 \mathrm{~cm}$ and the catalyst was fixed from both sides by quartz wool. XAS was performed at the Fe K-edge $(7.112 \mathrm{keV})$ in fluorescence mode and at the Mo K-edge (20.000 keV) in transmission mode quasisimultaneously by using the fast edge changing facility at the beamline. A molybdenum foil was measured simultaneously as a reference compound for energy calibration. The measurements were conducted in a loop that consisted of two Mo K-edge scans (4 min each), three Fe K-edge scans ( 5 min each) and one XRD pattern $(1 \mathrm{~min})$. Switching between Fe K- and Mo K-energies took approximately $30 \mathrm{~s}$ and switching from XAS to XRD monochromator and detector took $60 \mathrm{~s}$. 


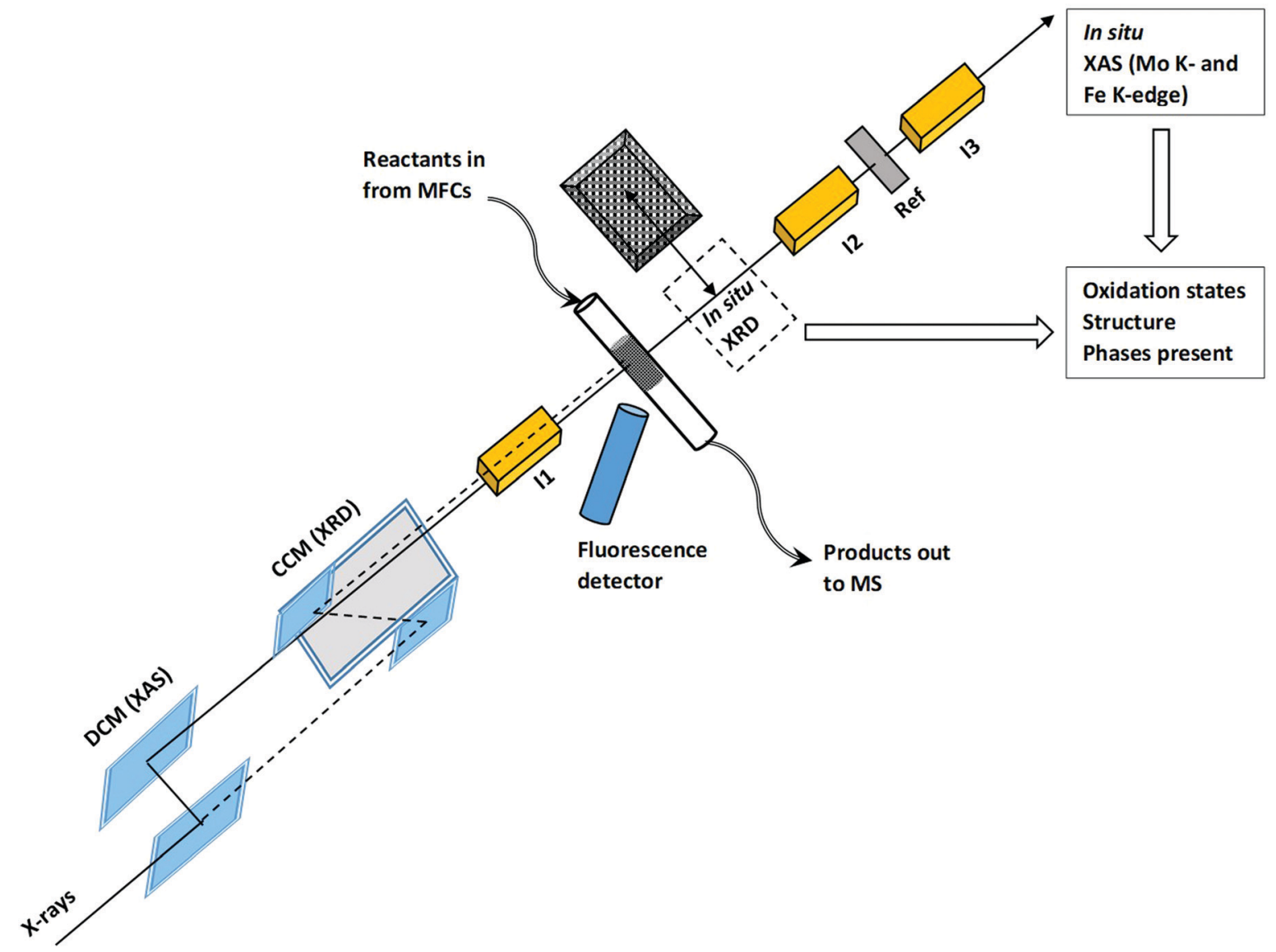

Fig. 1 Schematic setup for in situ XAS/XRD experiments performed at the unique setup at SNBL beamline BM31, ESRF. Double crystal monochromator (DCM), channel-cut monochromator (CCM), ionization chambers (11, 12 and I3), reference foil (Ref), mass flow controllers (MFCs) and mass spectrometer (MS).

The overview of the experimental procedure followed during in situ experiments is given in the ESI, $\dagger$ Fig. S1. The catalyst was first heated to $100{ }^{\circ} \mathrm{C}$ in a flow of $10 \% \mathrm{O}_{2} / \mathrm{He}$. Then the flow was changed to $5 \% \mathrm{MeOH} / \mathrm{He}$ and the sample was heated to $400{ }^{\circ} \mathrm{C}$ at $1{ }^{\circ} \mathrm{C} \mathrm{min}^{-1}$ for temperature programmed reduction (TPR) and was kept at $400{ }^{\circ} \mathrm{C}$ for 1 hour. The sample was cooled to $200{ }^{\circ} \mathrm{C}$ after which the flow was changed back to $10 \% \mathrm{O}_{2} / \mathrm{He}$. In the next step, the sample was heated to $500{ }^{\circ} \mathrm{C}$ at $1{ }^{\circ} \mathrm{C} \mathrm{min}{ }^{-1}$ for temperature programmed oxidation (TPO) and after a stabilization period of 1 hour finally cooled to $100{ }^{\circ} \mathrm{C}$.

XAS data were treated with the software package IFEFFIT. ${ }^{25}$ The spectra were energy calibrated, normalized, and background subtracted in Athena. Linear combination fitting (LCF) of XANES spectra was performed in a range of -20 to $+50 \mathrm{eV}$ at the Mo Kand Fe K-edges, respectively. EXAFS fitting was performed in Artemis by using model structures obtained from references of $\mathrm{Fe}_{2}\left(\mathrm{MoO}_{4}\right)_{3}$ and $\mathrm{MoO}_{3}$, in the case of Mo. At the Fe K-edge, spectra were only measured in the XANES region due to high noise in the EXAFS region. Fittings at the Mo K-edge were performed in $R$ - as well as $k$-space for determining the structural parameters which included energy shift of the path $\left(\Delta E_{0}\right)$, change in the half path length $(\Delta R)$, amplitude reduction factor $\left(S_{0}{ }^{2}\right)$, number of identical paths $(N)$ and relative mean-square displacement of the atoms included in the path (Debye-Waller factor, $\sigma^{2}$ ).
Principal component analysis (PCA) at the Fe K-edge was performed using XANES spectra in the range of -20 to $+80 \mathrm{eV}$ using the PCA subroutine of Demeter. ${ }^{25}$

XRD patterns were recorded with a CMOS-Dexela 2D detector at a short X-ray wavelength of $0.4934 \AA(25.13 \mathrm{keV})$ so that the penetration of X-rays is optimal. For each diffractogram, five bright and additionally five dark images for background subtraction were recorded in the $2 \theta$ range of $2-35^{\circ}$ with a data point spacing of approximately $0.01^{\circ}$ and subsequently averaged. The sample to detector distance was calibrated with a $\mathrm{LaB}_{6}$ reference. For XRD data treatment, the diffractograms were normalized to the most intense reflection of the $\mathrm{SiO}_{2}$ dilutant, and a normalized diffractogram of only the dilutant measured at the same temperature was subtracted using an in-house Matlab script.

\section{Results and discussion}

\subsection{Initial state and temperature programmed reduction} (TPR)

3.1.1 In situ observations at the Mo K-edge. Fig. 2 shows the in situ Mo K-XANES spectra of the FeMo catalyst during heating under reducing conditions of $5 \% \mathrm{MeOH} / \mathrm{He}$ (TPR). 


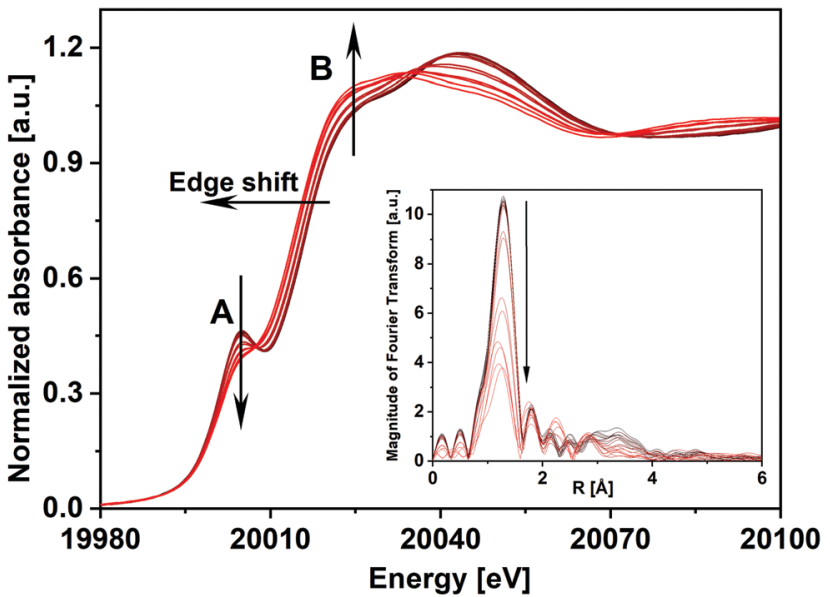

Fig. 2 In situ Mo K-edge XANES spectra and corresponding $k^{3}$-weighted Fourier transformed EXAFS spectra (inset) of the FeMo catalyst during TPR under $5 \% \mathrm{MeOH} / \mathrm{He}$. Arrows point towards increasing temperature.

For comparison, ex situ XANES spectra of the FeMo catalyst at $100{ }^{\circ} \mathrm{C}$ along with spectra of the reference samples $\mathrm{Fe}_{2}\left(\mathrm{MoO}_{4}\right)_{3}$ and $\alpha-\mathrm{MoO}_{3}$ are shown in ESI, $\dagger$ Fig. S2. The Mo K-XANES spectra exhibit a pre-edge peak $\mathrm{A}$ at $\sim 20007 \mathrm{eV}$ and another feature B at $20027 \mathrm{eV}$. The pre-edge peak A is attributed to the dipole-forbidden/quadrupole-allowed 1s-4d transition, which is associated primarily with tetrahedral geometry. The feature is also present but to weaker extent in distorted octahedral geometry. Feature B at $20027 \mathrm{eV}$ is assigned to the dipoleallowed 1s-5p transition, a characteristic feature of Mo species with octahedral/distorted octahedral geometry. ${ }^{26}$ A comparison of the XANES spectrum of the FeMo catalyst with $\mathrm{MoO}_{3}$ showed that the catalyst had a slightly stronger feature A than for $\mathrm{MoO}_{3}$ and weaker intensity for peak B. Also, the intensity of peak A for the catalyst was considerably lower compared to the reference spectrum of $\mathrm{Fe}_{2}\left(\mathrm{MoO}_{4}\right)_{3} \cdot{ }^{27}$ This showed that in the FeMo catalyst, Mo had both tetrahedral $\left(\mathrm{Fe}_{2}\left(\mathrm{MoO}_{4}\right)_{3}\right.$ nature) as well as octahedral geometry $\left(\mathrm{MoO}_{x}\right.$ nature, i.e., molybdenum oxide with an average oxidation state between $\mathrm{Mo}(\mathrm{Iv})$ to $\mathrm{Mo}(\mathrm{vI})$ ).

As the initial state of the FeMo catalyst at $100{ }^{\circ} \mathrm{C}$ indicated mixed Mo(vi) phases, linear combination fitting (LCF) of the XANES spectrum was performed with standards $\mathrm{Fe}_{2}\left(\mathrm{MoO}_{4}\right)_{3}$ and $\alpha-\mathrm{MoO}_{3}$. This showed $76 \%$ contribution from ferric molybdate and $24 \%$ contribution from molybdenum trioxide. This is in agreement with the composition of the fresh catalyst as determined by XRD containing 83 wt $\% \mathrm{Fe}_{2}\left(\mathrm{MoO}_{4}\right)_{3}$ and $17 \mathrm{wt} \%$ $\alpha-\mathrm{MoO}_{3}$, which corresponds to $22 \mathrm{~mol} \%$ of the Mo bound as $\mathrm{MoO}_{3}$ and $78 \mathrm{~mol} \%$ as $\mathrm{Fe}_{2}\left(\mathrm{MoO}_{4}\right)_{3}{ }^{7}$

The XANES features of the spectra during TPR (Fig. 2) showed that the edge position shifted to lower energies, from 20012.3 to $20010.2 \mathrm{eV}$, revealing partial reduction of Mo. The decrease in intensity of peak A and simultaneous increase in the intensity of feature $\mathrm{B}$ showed a rise in the octahedral nature of Mo centers, corresponding to $\mathrm{Fe}_{2}\left(\mathrm{MoO}_{4}\right)_{3}$ being decomposed to $\mathrm{FeMoO}_{4}$ and thereby forming $\mathrm{MoO}_{x}$ species e.g. $\mathrm{MoO}_{2}$ and intermediate $\mathrm{MoO}_{x}(x=2-3)$ species. However, it can be seen that after TPR, peak A was still present showing that Mo(vI) was not completely reduced to Mo(Iv), which does not have this feature. Since $\mathrm{MoO}_{2}$ has a strictly octahedral field, the 1s-4d transition is forbidden and no pre-edge peak would be observed. ${ }^{28}$ The corresponding Fourier transformed EXAFS spectra during TPR are shown in the inset of Fig. 2 where in the initial state of the catalyst a high amplitude of the first peak $\left(\mathrm{Mo}-\mathrm{O}_{1}\right)$ indicated strong tetrahedral nature due to a high content of $\mathrm{Fe}_{2}\left(\mathrm{MoO}_{4}\right)_{3}$. Metal backscattering at $\sim 3 \AA$ (Fe) additionally indicated the presence of $\mathrm{Fe}_{2}\left(\mathrm{MoO}_{4}\right)_{3} \cdot{ }^{26}$ The fitting results for the initial state of the catalyst at $100{ }^{\circ} \mathrm{C}$ in $10 \% \mathrm{O}_{2} / \mathrm{He}$ (see ESI, $\dagger$ Table S1) also supported the presence of multiple Mo phases (see also ESI, $\dagger$ Fig. S3(a)). At about $290{ }^{\circ} \mathrm{C}$, this metal backscattering disappeared due to the reduction of $\mathrm{Fe}_{2}\left(\mathrm{MoO}_{4}\right)_{3}$ (Fig. S3(b), ESI $\dagger$ ). In the final state during TPR at $350{ }^{\circ} \mathrm{C}$, the amplitude of the $\mathrm{Mo}-\mathrm{O}_{1}$ contribution was highly reduced showing the presence of disordered Mo oxide phases (Fig. S3(c), ESI $\dagger$ ).

In order to determine the contribution of different phases during the TPR, LCF was performed using standard spectra of $\mathrm{Fe}_{2}\left(\mathrm{MoO}_{4}\right)_{3}, \mathrm{MoO}_{3}$ and $\mathrm{MoO}_{2}$. FeMoO 4 was not available as reference due to unavailability of this compound commercially and its instability during synthesis. Also, at the Mo K-edge weak XANES features present in the $\mathrm{FeMoO}_{4}$ phase were found to be overlapping with strong features of the $\mathrm{Mo}(\mathrm{vI})$ phases $\mathrm{Fe}_{2}\left(\mathrm{MoO}_{4}\right)_{3}$ and $\mathrm{MoO}_{3}$ (for details see ESI, $\dagger$ Fig. S4). Thus, the formation of $\mathrm{FeMoO}_{4}$, and associated reduction of iron, is measured and discussed more clearly using Fe K-edge XANES in Section 3.1.2. It is worth mentioning here that PCA cannot be applied at Mo K-edge due to the unavailability of set of proper standard spectra. The contributions of the different phases obtained from LCF analysis of the XANES spectra at the Mo K-edge during TPR are shown in Fig. 3(a). Reduction of Mo started at approximately $270{ }^{\circ} \mathrm{C}$ and the contribution from $\mathrm{MoO}_{2}$ was observed at the expense of an initial decrease in $\mathrm{MoO}_{3}$ content. In the final state at $400{ }^{\circ} \mathrm{C}$, contributions from $\mathrm{Fe}_{2}\left(\mathrm{MoO}_{4}\right)_{3}, \mathrm{MoO}_{3}$ and $\mathrm{MoO}_{2}$ were observed to be $43 \%, 20 \%$ and $37 \%$, respectively. Note that $\mathrm{MoO}_{3}$ and $\mathrm{Fe}_{2}\left(\mathrm{MoO}_{4}\right)_{3}$ together represent the $\mathrm{Mo}(\mathrm{vI})$ present as $\mathrm{FeMoO}_{4}$ after reduction, see also Fe K-edge XANES and XRD results in Section 3.1.2. Thus, at $400{ }^{\circ} \mathrm{C}$, about $40 \%$ of the $\mathrm{Mo}(\mathrm{vI})$ species were reduced to $\mathrm{Mo}(\mathrm{IV})$ species, represented by $\mathrm{MoO}_{2}$. Some $\mathrm{MoO}_{x}(x=2-3)$ may also be presented by a combined contribution from $\mathrm{MoO}_{3}$ and $\mathrm{MoO}_{2}$ as it is hard to detect these species by their XANES fingerprint. More than $50 \%$ of the Mo was still present in oxidation state VI, which is in agreement with a previous in situ catalytic study ${ }^{9}$ at $250{ }^{\circ} \mathrm{C}$, which showed that during formaldehyde production only $\mathrm{Mo}(\mathrm{vI})$ was present throughout the experiment, indicating that gas phase oxygen transfer to molybdenum is rapid under reaction conditions at temperatures near the lower range of industrial conditions (typically 220 to $350{ }^{\circ} \mathrm{C}$ ).

Corresponding EXAFS spectra were analyzed by performing fitting in $R$-space and variation of selected obtained parameters are given in Fig. 3(b). Initially at $100{ }^{\circ} \mathrm{C}$, the $\mathrm{CN}$ of Mo-O1 was found to be $5.0( \pm 0.4)$ at $1.76 \AA$, which indicates strong contribution from the tetrahedral Mo centers present in $\mathrm{Fe}_{2}\left(\mathrm{MoO}_{4}\right)_{3}$. A considerable decrease in the $\mathrm{CN}$ of Mo-O1 was observed at approximately $290{ }^{\circ} \mathrm{C}$ (see also Fig. S3(b, c) and Table S2, ESI $\dagger$ ). 


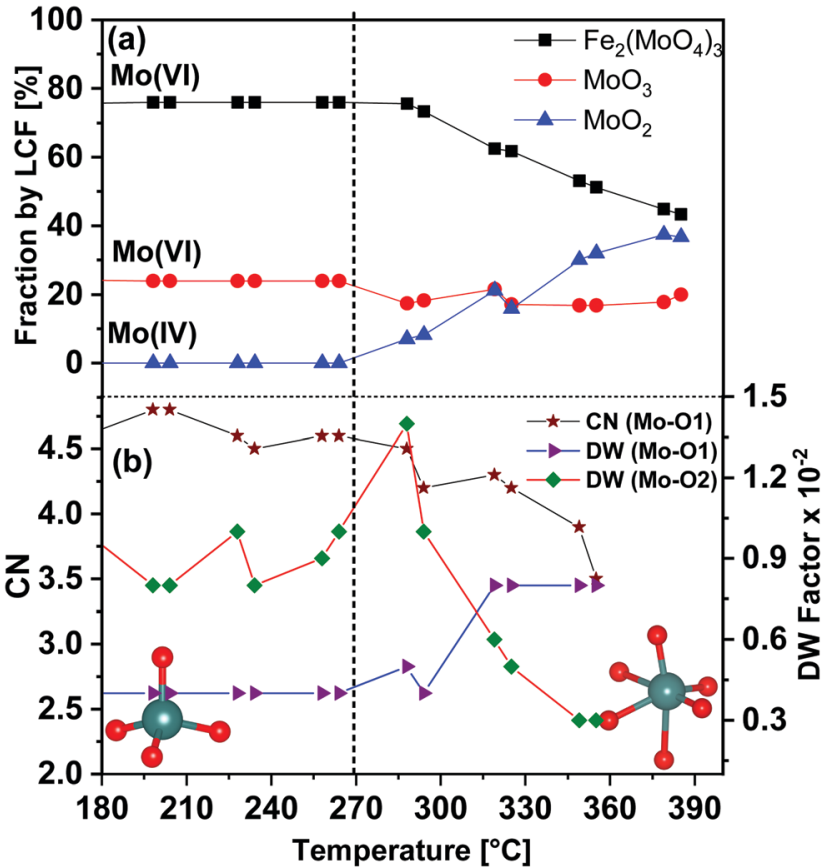

Fig. 3 (a) Mo K-edge XANES linear combination fitting (LCF) results for the FeMo catalyst during heating under $5 \% \mathrm{MeOH} / \mathrm{He}$ employing XANES spectra of the reference compounds $\mathrm{Fe}_{2}\left(\mathrm{MoO}_{4}\right)_{3}, \mathrm{MoO}_{3}$ and $\mathrm{MoO}_{2}$. (b) Variation in the selected parameters during TPR as determined from EXAFS fitting analysis in $R$ space. Dashed line indicates the temperature at which Mo reduction started. The insets show the transition from tetrahedral to octahedral coordination geometry of Mo during TPR, Mo (blue spheres) and $\mathrm{O}$ (red spheres). $\mathrm{CN}$ of Mo-O2 bonds were kept fixed to 1 .

Also, the DW factor for Mo-O1 started increasing in parallel with the reduction process and was almost doubled at the end of TPR, showing higher disorder in these bonds. Conversely, the DW factor for the longer Mo-O2 bonds (axial position), which corresponds to octahedral Mo centers, decreased at higher temperature showing stronger axial bonds due to an increase in octahedral nature of Mo centers present in $\mathrm{MoO}_{x}$ species (the $\mathrm{CN}$ of each of Mo-O2 bond were fixed to 1). Hence, with increasing temperature, a decrease in Mo oxidation state and an increase in octahedral nature of Mo centers were observed. These structural changes point towards formation of $\mathrm{MoO}_{2}$ and as well as $\mathrm{MoO}_{x}$ species during TPR (see also Fe K-edge XANES and XRD results in Section 3.1.2).

3.1.2 In situ observations by Fe K-edge XAS and XRD. Fig. 4(a) shows the in situ Fe K-XANES spectra during TPR, measured in the loop with Mo K-edge spectra to simultaneously probe the oxidation state and phase transitions of Fe. The features observed for the initial state of $\mathrm{Fe}$ at $100{ }^{\circ} \mathrm{C}$ show similarity with the $\mathrm{Fe}_{2}\left(\mathrm{MoO}_{4}\right)_{3}$ spectral features reported earlier. ${ }^{29}$ Initially, the Fe K-edge absorption peak maxima was observed at $7131.8 \mathrm{eV}$, which is similar to the value reported in literature. ${ }^{29}$ At higher temperature, the spectra exhibited a gradual shift towards lower energy indicating a change in the average oxidation state of Fe from III to II, mainly corresponding to formation of $\mathrm{FeMoO}_{4}$, however the presence of other $\mathrm{Fe}(\mathrm{II})$ species cannot be ruled out. In the temperature
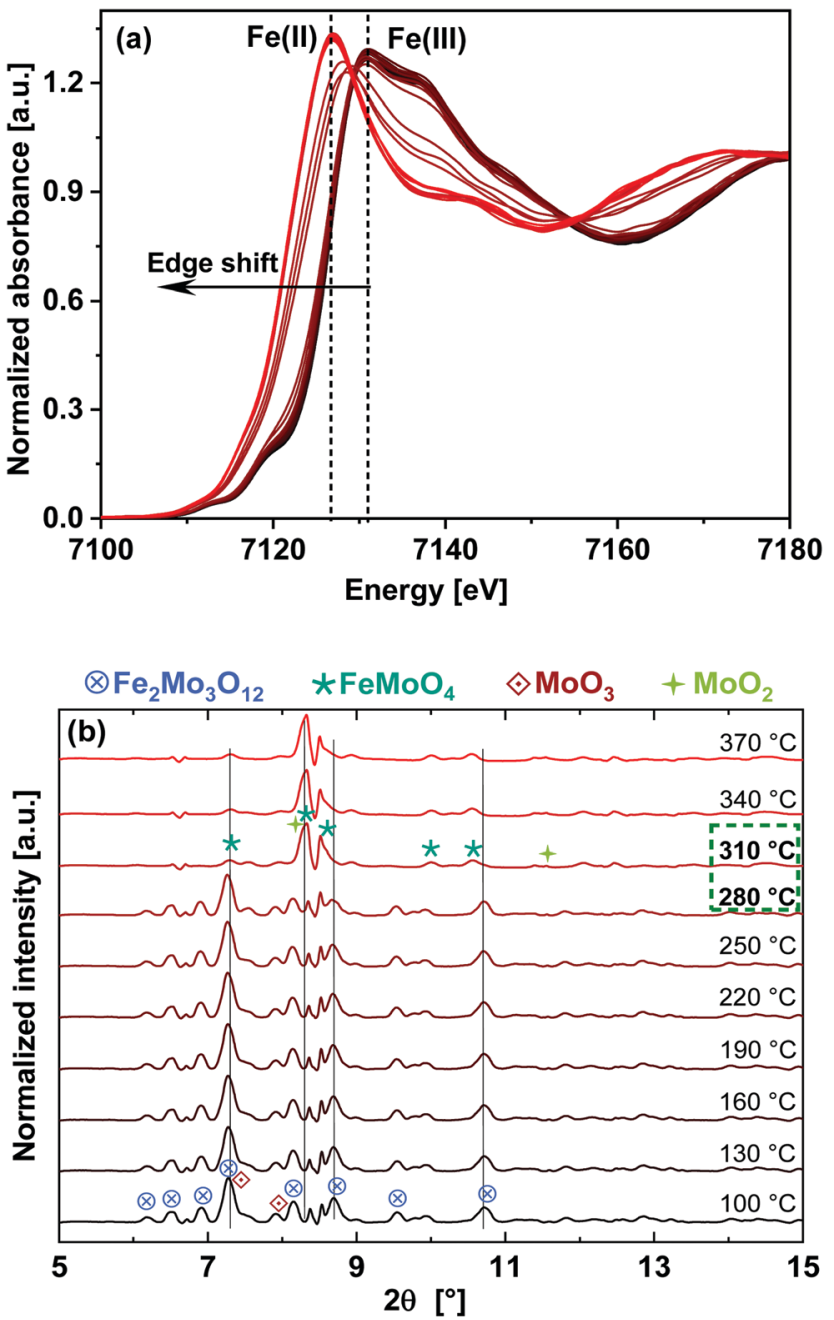

Fig. 4 (a) In situ Fe K-edge XANES spectra for the catalyst during heating in $5 \% \mathrm{MeOH} / \mathrm{He}$ (TPR). Dashed lines indicate the energy positions of the white line peak for oxidized and reduced Fe phases. The arrow points towards increasing temperature. (b) In situ XRD at $0.4934 \AA$ (25.13 keV) during TPR in $5 \% \mathrm{MeOH} / \mathrm{He}$. Phase transition to $\mathrm{FeMoO}_{4}$ can be observed by the increasing intensity of the reflections at 8.32 and $8.50^{\circ}$.

range $200-300{ }^{\circ} \mathrm{C}$, the presence of iron oxides such as $\mathrm{Fe}_{2} \mathrm{O}_{3}$ and $\mathrm{FeO}$ were also expected as intermediate phases. Hence, PCA was performed over Fe K-edge XANES spectra measured in this temperature range to confirm the number components required to fit the spectra by LCF analysis.

PCA uses matrix operations on an experimental spectra data matrix, to give two main outputs in the form of eigenvectors and eigenvalues, thereby providing the minimum number of significant components required to satisfactorily regenerate the data matrix. ${ }^{30}$ Thus, absorbance in a set of spectra can be mathematically modelled as a linear sum of individual components, called factors, which correspond to each one of the species present in the sample, plus noise. The PCA result at $275{ }^{\circ} \mathrm{C}$ is given as an example in the ESI, $\dagger$ Fig. S5 and Table S3. The figure shows the different components weighted by their eigenvalues where the first two components clearly dominate the spectra and the contribution from the third component is 
also significant. The fourth component appears to be noise, indicating that 3 components were required to fit the data. Thus, both $\mathrm{Fe}_{2} \mathrm{O}_{3}$ and $\mathrm{FeO}$ were evaluated as standards during LCF, but $\mathrm{Fe}_{2} \mathrm{O}_{3}$ gave better fit results, confirming its presence as intermediate phase during TPR $\left(200-300{ }^{\circ} \mathrm{C}\right)$.

Results obtained from LCF analysis performed using these XANES spectra are given in the ESI, $\dagger$ Fig. S6. It was observed that the reduction of Fe starts at approximately $270{ }^{\circ} \mathrm{C}$, parallel to reduction of Mo. $\mathrm{Fe}(\mathrm{ox})$ is the initial state which mainly corresponds to $\mathrm{Fe}_{2}\left(\mathrm{MoO}_{4}\right)_{3}$ and $\mathrm{Fe}(\mathrm{red})$ is the final state after TPR, which have been taken as the standards for LCF analysis. The final reduced state of $\mathrm{Fe}$, having features similar to $\mathrm{FeMoO}_{4},{ }^{29}$ was observed at $330{ }^{\circ} \mathrm{C}$, showing faster reduction of Fe compared to Mo. These results, combined with the Mo K-edge results, indicate that at the end of TPR at $400{ }^{\circ} \mathrm{C}$, the phases present were $\mathrm{Fe}_{2}\left(\mathrm{MoO}_{4}\right)_{3}, \mathrm{FeMoO}_{4}$, and $\mathrm{MoO}_{2}$ (possibly including intermediate phases $\mathrm{MoO}_{x}$ ), which confirm the presence of both $\mathrm{Mo}(\mathrm{Iv})$ and $\mathrm{Mo}(\mathrm{vI})$ species.

Due to the fast interchange between the monochromators, DCM for XAS and CCM for XRD, the XAS measurements at the Mo K- and Fe K-edges were further supported by quasisimultaneously recorded XRD patterns of the FeMo catalyst during TPR under $5 \% \mathrm{MeOH} / \mathrm{He}$, as shown in Fig. 4 (b). An XRD pattern characteristic for $\mathrm{Fe}_{2}\left(\mathrm{MoO}_{4}\right)_{3}$ (most intense reflection at $2 \theta=7.32^{\circ}$ and other significant reflections at 6.93, 7.55-7.63, $\left.7.92,8.16,8.73-8.82^{\circ}\right)$ at the beginning of the TPR was observed, which disappeared almost completely at $310^{\circ} \mathrm{C}$ and reflections corresponding to $\mathrm{FeMoO}_{4}$ appeared (reflections at 8.32 and $8.50^{\circ}$ ). Furthermore, at the end of TPR a weak reflection from $\mathrm{MoO}_{2}$ was also observed at $11.6^{\circ}$. In the initial state, reflections from $\alpha-\mathrm{MoO}_{3}$ were observed as well (reflections at 7.43 and $8.16-8.23^{\circ}$ ), partly overlapping with the reflections of $\mathrm{Fe}_{2}\left(\mathrm{MoO}_{4}\right)_{3}$, which disappeared as well. Thus, in situ XRD confirms that the phase transformation of $\mathrm{Fe}_{2}\left(\mathrm{MoO}_{4}\right)_{3}$ to $\mathrm{FeMoO}_{4}$ started at around $280{ }^{\circ} \mathrm{C}$, in agreement with XAS results at the Mo K- and Fe K-edges.

3.1.3 Gas phase composition during TPR. The corresponding evolution of the gas phase composition during TPR, overlaid with the fraction of Mo(Iv) (from Mo K-edge LCF), Fe(III) and Fe(II) (from Fe K-edge LCF) is shown in Fig. 5 (feed gas composition of $5 \% \mathrm{MeOH} / \mathrm{He}$ ). It can be observed from the figure that at $\sim 270{ }^{\circ} \mathrm{C}$ reduction of $\mathrm{Fe}$ started almost simultaneously with Mo. Here, the Fe(II) fraction obtained from Fe K-edge LCF represent $\mathrm{FeMoO}_{4}$ as no other Fe(II) species were confirmed by LCF, which indicate formation of $\mathrm{FeMoO}_{4}$ from $\mathrm{Fe}_{2}\left(\mathrm{MoO}_{4}\right)_{3}$. Looking at the MS trace, the concentration of $\mathrm{MeOH}$ was observed to decrease in this temperature range, confirming the reaction of methanol with the catalyst in the temperature range from 260 to $400{ }^{\circ} \mathrm{C}$. When staying at this temperature for $1 \mathrm{~h}$, the methanol concentration increased to almost its initial value as shown in the extended $X$-axis of Fig. 5 for the isothermal period (red line) starting at $400{ }^{\circ} \mathrm{C}$.

Though the MS-traces $\mathrm{m} / \mathrm{z}=29$ and 18 corresponding to the formation of $\mathrm{HCHO}$ and $\mathrm{H}_{2} \mathrm{O}$, respectively, have also been observed as shown in the ESI, $\dagger$ Fig. S7, the MS was slow at pumping down from the previous experiment performed.

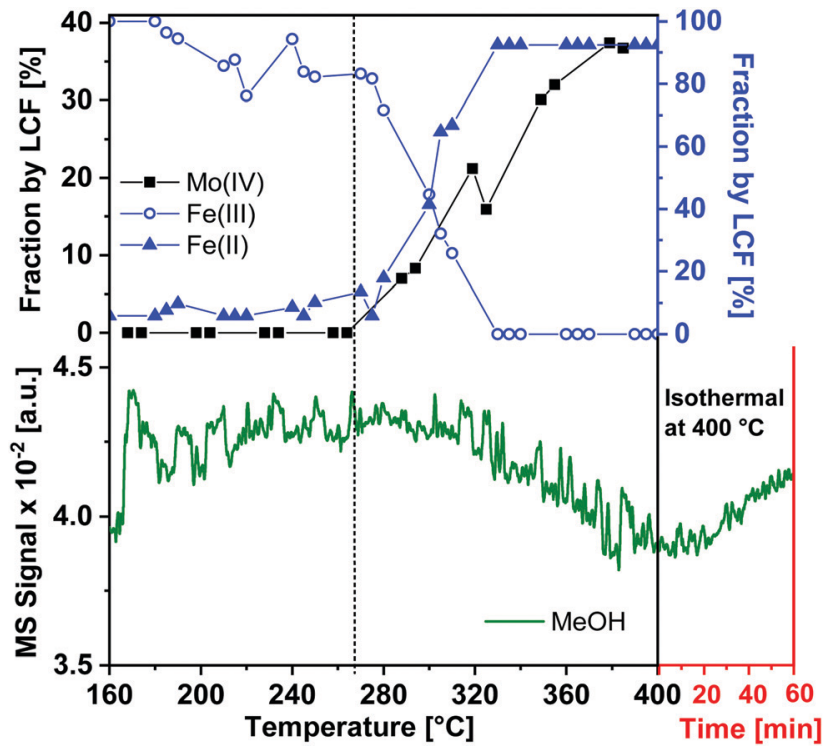

Fig. 5 Fraction of Mo(IV) (as determined from Mo K-edge LCF), Fe(III) and $\mathrm{Fe}$ (II) (from Fe K-edge LCF) as function of temperature with MS trace of $\mathrm{MeOH}$ overlaid during heating (100 to $400{ }^{\circ} \mathrm{C}$ at $1{ }^{\circ} \mathrm{C} \mathrm{min}^{-1}$ ) under reducing conditions of $5 \% \mathrm{MeOH} / \mathrm{He}$. The extended $X$-axis (in red) shows the isothermal period at $400{ }^{\circ} \mathrm{C}$ for the next 60 minutes. The dashed line indicates the start of reduction of Mo as well as Fe species.

Hence there was remarkably high background signal of $\mathrm{HCHO}$ and $\mathrm{H}_{2} \mathrm{O}$ during the TPR up to about $300{ }^{\circ} \mathrm{C}$. Nevertheless, it can be observed from Fig. S7 (ESI $\dagger$ ) that during heat up the concentration of $\mathrm{MeOH}$ decreased and those of $\mathrm{HCHO}$ and $\mathrm{H}_{2} \mathrm{O}$ increased, as expected, and during the isothermal period, when the reduction was complete, the concentration of $\mathrm{MeOH}$ increased and those of $\mathrm{HCHO}$ and $\mathrm{H}_{2} \mathrm{O}$ decreased, both with some delay due to the MS pumping down.

Hence, using in situ XAS/XRD with MS measurements of the gas phase, it can be concluded that during heating under reducing conditions, $\mathrm{Fe}_{2}\left(\mathrm{MoO}_{4}\right)_{3}$ and $\mathrm{MoO}_{3}$ were observed to reduce thereby forming $\mathrm{FeMoO}_{4}$ and $\mathrm{MoO}_{2}$ which is in agreement with the proposed reactions (1) and (2).

$$
\mathrm{Fe}_{2}\left(\mathrm{MoO}_{4}\right)_{3}+\mathrm{CH}_{3} \mathrm{OH} \rightarrow 2 \mathrm{FeMoO}_{4}+\mathrm{MoO}_{3}+\mathrm{HCHO}+\mathrm{H}_{2} \mathrm{O}
$$

$$
\mathrm{MoO}_{3}+\mathrm{CH}_{3} \mathrm{OH} \rightarrow \mathrm{MoO}_{2}+\mathrm{HCHO}+\mathrm{H}_{2} \mathrm{O}
$$

As described earlier, after TPR the catalyst was kept isothermal at $400{ }^{\circ} \mathrm{C}$ in $5 \% \mathrm{MeOH} / \mathrm{He}$ for 1 hour. Then the temperature was lowered to $200{ }^{\circ} \mathrm{C}$ and after stabilization at $200{ }^{\circ} \mathrm{C}$ the gas conditions were changed to $10 \% \mathrm{O}_{2} / \mathrm{He}$ (ESI, $\dagger$ Fig. S1). The phases of the catalyst remained mainly intact during the cool down, as well as during switching to oxidizing conditions as indicated by the XAS/XRD results given in the ESI, $\dagger$ Fig. S8. At the Mo K-edge a slight shift of the edge was observed towards lower energies owing to a small increase in reduced phases of Mo. At the Fe K-edge in the post edge region some features were enhanced, indicating less distortion in the structure of $\mathrm{Fe}$ species after cooling down. 


\subsection{Heating under oxidizing conditions (TPO)}

3.2.1 In situ XAS at Mo and Fe K-edges and XRD. Fig. 6(a) shows the in situ Mo K-edge XANES spectra of the catalyst during heating under oxidizing conditions (TPO) after the TPR and cool down to $200{ }^{\circ} \mathrm{C}$ in $5 \% \mathrm{MeOH} / \mathrm{He}$. The edge position shifted towards higher energies showing an increase in the oxidation state of Mo, as expected. The pre-edge peak A regained intensity lost during TPR, corresponding to an increase in tetrahedral nature of the Mo centers, and the simultaneous weakening of feature B indicated lowering of octahedral nature.

LCF analysis of the XANES spectra using the same standards as during TPR and variations of the parameters obtained from EXAFS analysis are shown in Fig. 6(b) in the temperature range $320-500{ }^{\circ} \mathrm{C}$ (for the complete LCF results from $200-500{ }^{\circ} \mathrm{C}$ please see ESI, $\dagger$ Fig. S9). The initial composition before TPO at $200{ }^{\circ} \mathrm{C}$ was $39 \% \mathrm{Fe}_{2}\left(\mathrm{MoO}_{4}\right)_{3}, 20 \% \mathrm{MoO}_{3}$ and $41 \% \mathrm{MoO}_{2}$ which is similar to the composition of the final state after TPR $\left(43 \% \mathrm{Fe}_{2}\left(\mathrm{MoO}_{4}\right)_{3}, 20 \% \mathrm{MoO}_{3}\right.$ and $\left.37 \% \mathrm{MoO}_{2}\right)$ within the margin of error of LCF and considering the temperature difference.

Oxidation of Mo began as soon as the temperature started to rise which is evident from the decreasing $\mathrm{MoO}_{2}$ and increasing $\mathrm{Fe}_{2}\left(\mathrm{MoO}_{4}\right)_{3}$ contributions, showing that overall $\mathrm{MoO}_{2}$ combined with $\mathrm{FeMoO}_{4}$ to give $\mathrm{Fe}_{2}\left(\mathrm{MoO}_{4}\right)_{3}$. The content of $\mathrm{MoO}_{3}$ was quite stable until $380{ }^{\circ} \mathrm{C}$, but in the range of $380-400{ }^{\circ} \mathrm{C}$ a sharp increase was observed (Fig. 6(b)), indicating formation of $\mathrm{MoO}_{3}$ as well.

At the same temperature, the EXAFS parameters (Fig. 6(b)) showed a decrease in the DW factor of Mo-O1 and an increase in that of Mo-O2 supporting formation of octahedral Mo centers present in $\mathrm{MoO}_{3}$. The contribution from $\mathrm{MoO}_{2}$ continuously decreased and became negligible at around $500{ }^{\circ} \mathrm{C}$, showing that almost all of Mo was in the $\mathrm{Mo}(\mathrm{vI})$ state. After the sudden increase at approximately $390{ }^{\circ} \mathrm{C}$, the contribution from $\mathrm{MoO}_{3}$ fell back to $21 \%$, slightly lower than what was present initially before TPO $(24 \%)$. The remaining $80 \%$ of $\mathrm{Mo}(\mathrm{vI})$ was found to be
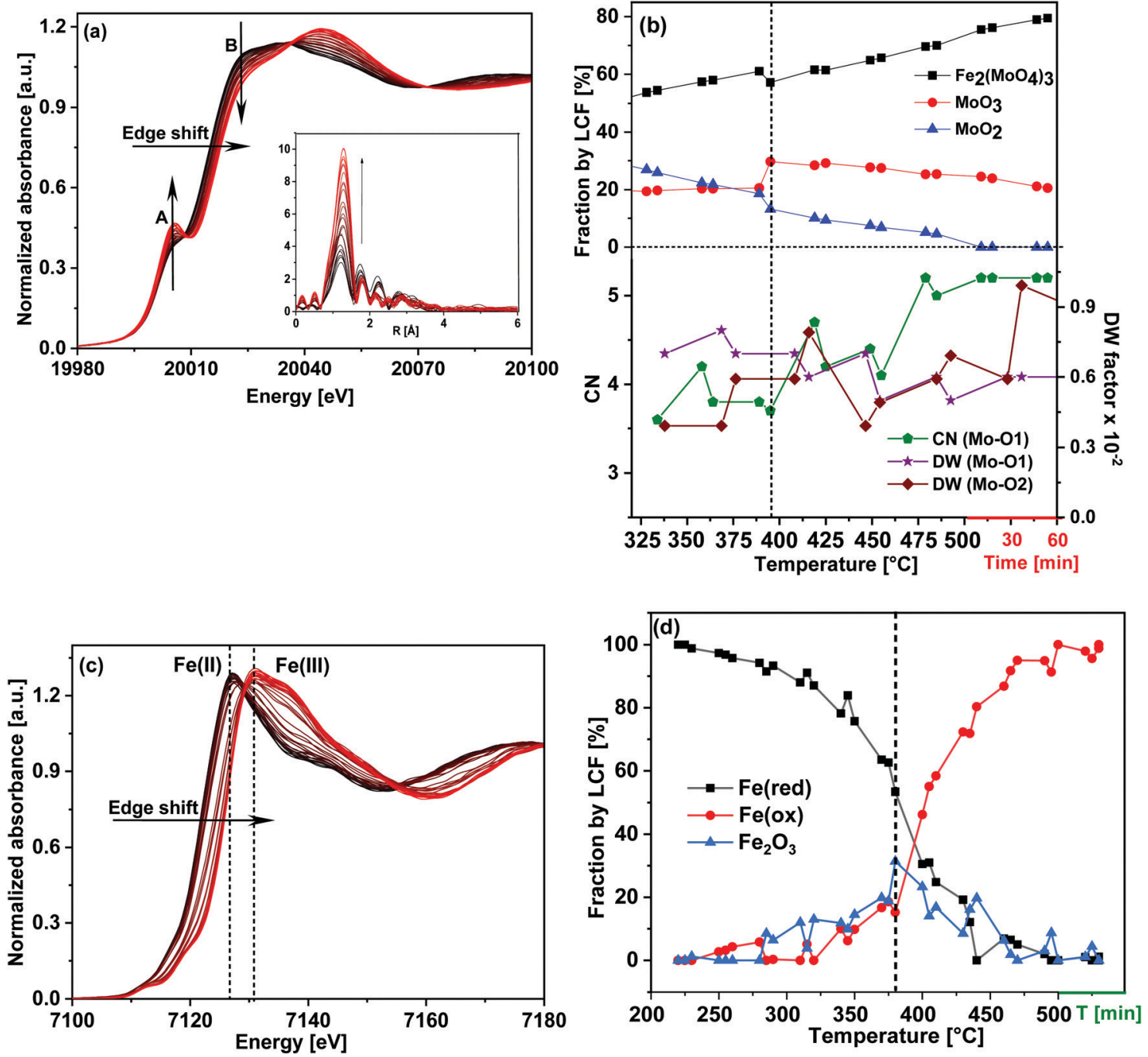

Fig. 6 For the FeMo catalyst during heating under oxidizing conditions 10\% $\mathrm{O}_{2} / \mathrm{He}$ (TPO): (a) Mo K-edge XANES spectra, (b) corresponding XANES LCF results and variation in the selected parameters as determined from EXAFS analysis. At the $X$-axis, the red line after $500{ }^{\circ} \mathrm{C}$ represents the isothermal period, (c) Fe K-edge XANES spectra and (d) corresponding XANES LCF results. In (a) and (c) arrows point towards increasing temperature. The vertical dashed lines in (b) and (d) indicate the temperature $\sim 390{ }^{\circ} \mathrm{C}$ at which a sudden increase in $\mathrm{MoO}_{3}$ and $\mathrm{Fe}_{2} \mathrm{O}_{3}$ content was observed, respectively. 
$\mathrm{Fe}_{2}\left(\mathrm{MoO}_{4}\right)_{3}$, which is slightly higher compared to the initial composition of the catalyst at $100{ }^{\circ} \mathrm{C}$ before TPR (76\%). It is possible that some $\mathrm{MoO}_{3}$ formed volatile species and evaporated during the TPR, similar to the evaporation clearly observed under reaction conditions for methanol oxidation. ${ }^{20}$ EXAFS analysis also confirmed this conclusion since the $\mathrm{CN}$ of Mo-O1 at $1.77 \AA$ increased and the corresponding DW factor decreased, showing a rise in tetrahedral nature of Mo. Similarly, the DW factor of the Mo-O2 (axial) concurrently increased, showing a decrease in octahedral nature of Mo centers (the $\mathrm{CN}$ of both Mo-O2 bonds were kept fixed to 1).

Fig. 6(c) shows the Fe K-edge XANES spectra during heating under oxidizing conditions. PCA was performed to confirm the number components required to fit the spectra and the results obtained from PCA analysis for Fe K-edge XANES spectrum at $380{ }^{\circ} \mathrm{C}$ is given as an example in ESI, $\dagger$ Fig. S10 and Table S4. In this case also, the first two components clearly dominate the spectra, with a significant contribution from the third component and the fourth component appears to be noise, indicating that 3 components were required to fit the data. Thus, $\mathrm{Fe}_{2} \mathrm{O}_{3}$ was also employed as standard during LCF, which gives better fit results than $\mathrm{FeO}$, confirming its presence as intermediate phase during TPO (300-450 $\left.{ }^{\circ} \mathrm{C}\right)$. LCF analysis shown in Fig. 6(d) showed that oxidation of Fe effectively started at $280{ }^{\circ} \mathrm{C}$. The contribution from $\mathrm{Fe}_{2} \mathrm{O}_{3}$ was found to be high (around 30\%) between $380-410{ }^{\circ} \mathrm{C}$. In this temperature range LCF at the Mo K-edge also showed a high presence of $\mathrm{MoO}_{3}$ pointing towards FeMoO 4 reacting with $\mathrm{O}_{2}$ to give $\mathrm{Fe}_{2} \mathrm{O}_{3}$ and $\mathrm{MoO}_{3}$ (eqn (3)) in competition with the reactions regenerating the catalyst (eqn (4) and (5)). ${ }^{31}$ However, like the excess $\mathrm{MoO}_{3}$, the $\mathrm{Fe}_{2} \mathrm{O}_{3}$ phase was an intermediate and the contribution was found to decrease at higher temperature. At $500{ }^{\circ} \mathrm{C}$ Fe was found mostly as $\mathrm{Fe}_{2}\left(\mathrm{MoO}_{4}\right)_{3}$, due to recombination of $\mathrm{Fe}_{2} \mathrm{O}_{3}$ and $\mathrm{MoO}_{3}$ by solid state reaction (eqn (6)). These redox dynamics explain the formation of $\mathrm{Fe}_{2} \mathrm{O}_{3}$ observed under reaction conditions for selective oxidation of methanol at 380 to $400{ }^{\circ} \mathrm{C}$, where $\mathrm{MoO}_{3}$ evaporation competes with the recombination and with extended time on stream $\mathrm{MoO}_{3}$ eventually evaporates completely. $^{7}$

Corresponding in situ XRD results are given in Fig. 7. They also show the presence of $\mathrm{FeMoO}_{4}$ and $\mathrm{MoO}_{2}$ initially, as observed at the end of TPR. During TPO, a phase transition was observed between $380-410{ }^{\circ} \mathrm{C}$ where higher presence of $\mathrm{MoO}_{3}$ (by LCF at Mo K-edge data) and $\mathrm{Fe}_{2} \mathrm{O}_{3}$ (by LCF at Fe K-edge data) were observed by XANES. Only $\mathrm{Fe}_{2}\left(\mathrm{MoO}_{4}\right)_{3}$ and $\mathrm{MoO}_{3}$ were observed as oxidation products by XRD, which agrees with the overall re-oxidation and recombination reactions given in eqn (3), (4) and (6). The $\mathrm{Fe}_{2} \mathrm{O}_{3}$ detected by LCF of the XANES data was an intermediate, possibly an amorphous, phase and thus was not detected by XRD.

$$
\begin{gathered}
2 \mathrm{FeMoO}_{4}+1 / 2 \mathrm{O}_{2} \rightarrow \mathrm{Fe}_{2} \mathrm{O}_{3}+2 \mathrm{MoO}_{3} \\
\mathrm{MoO}_{2}+1 / 2 \mathrm{O}_{2} \rightarrow \mathrm{MoO}_{3} \\
2 \mathrm{FeMoO}_{4}+\mathrm{MoO}_{3}+1 / 2 \mathrm{O}_{2} \rightarrow \mathrm{Fe}_{2}\left(\mathrm{MoO}_{4}\right)_{3} \\
\mathrm{Fe}_{2} \mathrm{O}_{3}+3 \mathrm{MoO}_{3} \rightarrow \mathrm{Fe}_{2}\left(\mathrm{MoO}_{4}\right)_{3}
\end{gathered}
$$

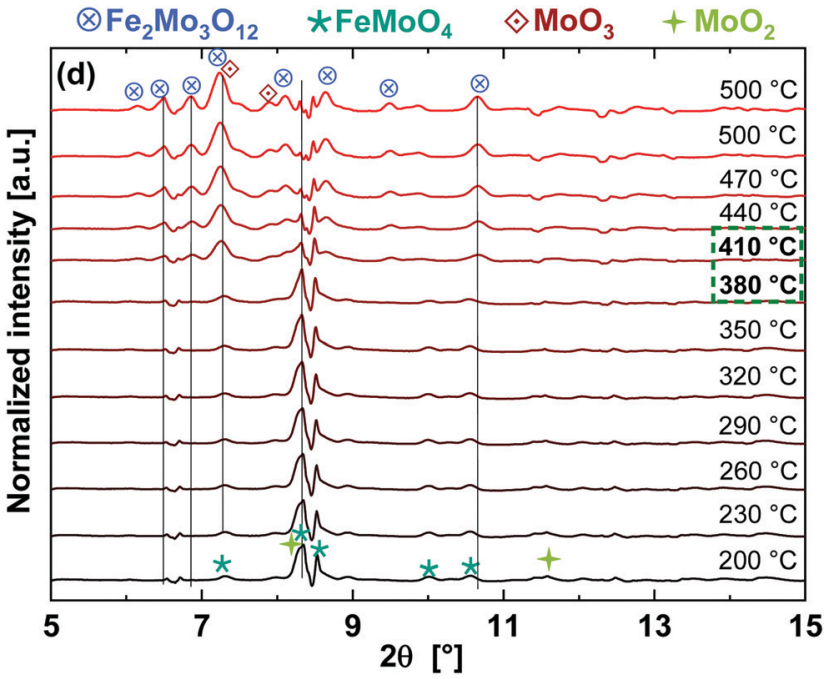

Fig. 7 XRD patterns at different temperatures during TPO (at $25.23 \mathrm{eV}$ corresponding to $\lambda=0.4934 \AA$ ) .

Overall, the results obtained from XRD correspond to those obtained from LCF of XANES showing that $\mathrm{FeMoO}_{4}$ and $\mathrm{MoO}_{2}$ were oxidized and recombined to form $\mathrm{Fe}_{2}\left(\mathrm{MoO}_{4}\right)_{3}$.

3.2.2 Reversibility of the reduction and re-oxidation. To check whether the changes that occurred during the complete cycle of TPR and TPO were reversible, the initial state of the catalyst at $100{ }^{\circ} \mathrm{C}$ before reduction, the state of the catalyst at $500{ }^{\circ} \mathrm{C}$ after reoxidation and the final state of the catalyst after cooling down to $100{ }^{\circ} \mathrm{C}$ were compared. Fig. 8(a-d) show the Mo K-edge XANES spectra, corresponding FT spectra, Fe K-edge XANES spectra and XRD reflections of the catalyst at these different stages of the redox cycle. The identical features observed in the Mo and Fe XANES showed that Mo and Fe have attained their initial state with respect to oxidation state and coordination geometry. Similar conclusions can be drawn from the corresponding XRD patterns showing the presence of identical phases at these stages, though at $500{ }^{\circ} \mathrm{C}$ there is a temperature shift.

In Fig. 8(b), the FT EXAFS spectra are given and Table 1 shows the fitting parameters (see also ESI, $\dagger$ Fig. S3(a, e and f)). The major difference was observed in the FT spectra in the region of 2.5-4.0 $\AA$ where there are backscattering peaks due to Mo-Fe and Mo-Mo contributions. The Mo-Mo peak at $3.7 \AA$ completely disappeared at $500{ }^{\circ} \mathrm{C}$ after the redox cycling, which indicates high distortions in the Mo-Mo metal shells related to the $\mathrm{MoO}_{3}$ phase. By cooling down to $100{ }^{\circ} \mathrm{C}$, this backscattering peak was observed to be regenerated indicating that the catalyst returns to its crystalline phase. At $500{ }^{\circ} \mathrm{C}$, the $\mathrm{CN}$ of the first peak (Mo-O1) was comparatively higher than its value at $100{ }^{\circ} \mathrm{C}$ in the initial as well as the final state, which indicate stronger tetrahedral nature of Mo coordination at higher temperature. In case of the longer axial Mo-O2 bonds, a considerable increase in the DW factor was observed between the initial and final states at $100{ }^{\circ} \mathrm{C}$. This indicates loss of octahedral character of the Mo centers during the redox cycle, corresponding to evaporation of some of the excess $\mathrm{MoO}_{3}$. However, changes in the $\mathrm{MoO}_{3}$ crystallite particle size or shape during the redox cycling may also occur. As the $\mathrm{CN}$ of $\mathrm{Mo}-\mathrm{O} 2$ 

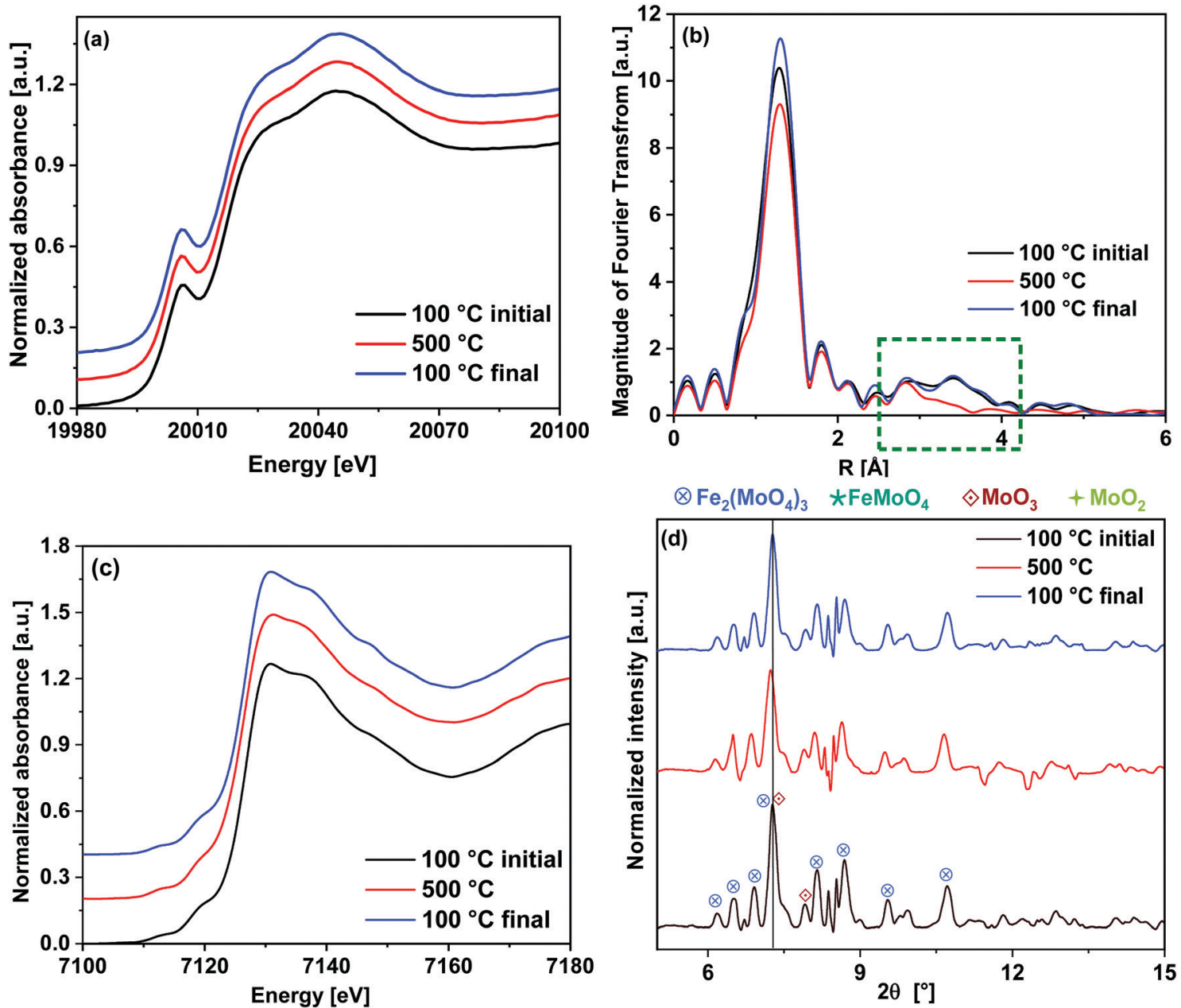

Fig. 8 Comparison of the initial state of the catalyst measured at $100{ }^{\circ} \mathrm{C}$, the state at $500{ }^{\circ} \mathrm{C}$ after TPO and the final state after cool-down to $100{ }^{\circ} \mathrm{C}$ under $10 \% \mathrm{O}_{2} / \mathrm{He}$ : (a) Mo K-edge XANES (b) corresponding $k^{3}$-weighted FT EXAFS spectra with marked region $2.5-4.0 \AA$. (c) Fe K-edge XANES and (d) XRD patterns with the assignment of phases.

Table 1 Structural parameters obtained from EXAFS fitting at Mo K-edge for the state of the catalyst at $500{ }^{\circ} \mathrm{C}$ after reduction and re-oxidation, compared to the initial state of the catalyst at $100{ }^{\circ} \mathrm{C}$ and final state after cooling to $100{ }^{\circ} \mathrm{C} . \Delta E_{0}=1.0$ and $\chi_{\nu}{ }^{2}=65$ for $500{ }^{\circ} \mathrm{C}, \Delta E_{0}=2.1$ and $\chi_{\nu}{ }^{2}=17$ for $100{ }^{\circ} \mathrm{C}$ (final)

\begin{tabular}{|c|c|c|c|c|c|c|c|c|c|}
\hline Path & \multicolumn{3}{|c|}{$100{ }^{\circ} \mathrm{C}$ (initial) } & \multicolumn{3}{|l|}{$500{ }^{\circ} \mathrm{C}$} & \multicolumn{3}{|l|}{$100{ }^{\circ} \mathrm{C}$ (final) } \\
\hline $\mathrm{Mo}-\mathrm{O}_{1}$ & $1.76 \pm 0.01$ & $5.0 \pm 0.5$ & $0.0046 \pm 0.0006$ & $1.77 \pm 0.02$ & $5.2 \pm 0.4$ & $0.0054 \pm 0.0007$ & $1.77 \pm 0.02$ & $4.3 \pm 0.4$ & $0.0030 \pm 0.0006$ \\
\hline Mo-Fe & $3.50 \pm 0.02$ & $1^{a}$ & $0.0064 \pm 0.0025$ & $3.5 \pm 0.06$ & $1^{a}$ & $0.0074 \pm 0.0031$ & $3.50 \pm 0.02$ & $1^{a}$ & $0.0064 \pm 0.0021$ \\
\hline Mo-Mo & $3.73 \pm 0.03$ & $1^{a}$ & $0.0064 \pm 0.0025$ & - & & & $3.7 \pm 0.03$ & $1^{a}$ & $0.0064 \pm 0.0021$ \\
\hline
\end{tabular}

${ }^{a}$ Fixed during the fitting.

bonds were kept fixed to the value of 1 , the DW factor obtained from the fitting corresponds to the strength of these bonds.

\section{Conclusions}

We have shown that the advanced setup at the synchrotron facilities makes it possible to obtain bulk structural as well as chemical information on the catalyst system under investigation. The combination of transmission XAS at the Mo K-edge, fluorescence XAS at the Fe K-edge and XRD at high energy proved to be a successful tool for detection of individual crystalline and amorphous phases in situ during the different stages of redox cycling of an iron molybdate catalyst with excess molybdenum trioxide, thereby providing important information about the phase transformations. The simplified 
reducing/oxidizing conditions employed in this study are needed to gain deeper insight into the catalytic system and catalytic cycle. Subsequent XAS measurements at the Mo K- and Fe K-edges showed that reduction of Mo as well as Fe started at $\sim 270{ }^{\circ} \mathrm{C}$ and at $400{ }^{\circ} \mathrm{C} \mathrm{MoO}_{2}$ and $\mathrm{FeMoO}_{4}$ were observed as reduced phases. Complete reduction of $\mathrm{Fe}(\mathrm{III})$ to $\mathrm{Fe}(\mathrm{II})$, forming $\mathrm{FeMoO}_{4}$, was observed at $330{ }^{\circ} \mathrm{C}$ whereas $60 \%$ Mo was still present as $\mathrm{Mo}(\mathrm{vI})$ after reduction at $400{ }^{\circ} \mathrm{C}$. Quasisimultaneously recorded in situ XRD at high energy confirmed that the phase transition from $\mathrm{Fe}_{2}\left(\mathrm{MoO}_{4}\right)_{3}$ and $\mathrm{MoO}_{3}$ to $\mathrm{FeMoO}_{4}$ and $\mathrm{MoO}_{2}$ occurred at about 280-300 ${ }^{\circ} \mathrm{C}$. Online gas phase analysis recorded simultaneously showed that the concentration of methanol decreased parallel to reduction of Fe and Mo observed by XAS and XRD, confirming the reaction between gas and solid.

Subsequent heating in an oxidative atmosphere from 200 to $500{ }^{\circ} \mathrm{C}$ caused $\mathrm{Mo}$ and $\mathrm{Fe}$ to reoxidize thereby forming $\mathrm{Fe}_{2}\left(\mathrm{MoO}_{4}\right)_{3}$. Intermediates phases $\mathrm{Fe}_{2} \mathrm{O}_{3}$ and excess $\mathrm{MoO}_{3}$ were also formed in parallel reactions, but they recombined above $400{ }^{\circ} \mathrm{C}$ to give $\mathrm{Fe}_{2}\left(\mathrm{MoO}_{4}\right)_{3}$, which was observed to be the most dominant phase at $500{ }^{\circ} \mathrm{C}$. XRD confirmed that the main transition occurred at about $380-400{ }^{\circ} \mathrm{C}$, at which rise in the $\mathrm{MoO}_{3}$ and $\mathrm{Fe}_{2} \mathrm{O}_{3}$ contributions were observed by XANES LCF.

The reduction/re-oxidation dynamics observed in this study, particularly the formation of $\mathrm{FeMoO}_{4}$ and $\mathrm{MoO}_{2}$ during reduction and $\mathrm{Fe}_{2} \mathrm{O}_{3}$ during re-oxidation, shows the segregation of iron and molybdenum (forming $\mathrm{FeMoO}_{4}$ and $\mathrm{Fe}_{2} \mathrm{O}_{3}$ ) observed under industrial reaction conditions, where the concurrent $\mathrm{MoO}_{3}$ evaporation hinders recombination to form $\mathrm{Fe}_{2}\left(\mathrm{MoO}_{4}\right)_{3}$, which results in catalyst deactivation and selectivity loss by iron enrichment. In the future, it would be helpful to receive complementary insight by more surface sensitive methods, typically only possible under quasi in situ conditions, or using samples with higher surface area that would enhance the sensitivity of XAS for the surface.

\section{Conflicts of interest}

The authors declare no competing financial interest.

\section{Acknowledgements}

We thank the Independent Research Fund Denmark for the financial support (grant no. DFF-4184-00336). We are grateful to ESRF for providing beamtime at the Swiss-Norwegian beamline BM31 for combined XAS/XRD studies and, in particular, to Dr Hermann Emerich and Dr Wouter van Beek for their help and technical support during XAS experiments. We thank MarcAndré Serrer (KIT) for his support during the beamtime and the HGF for support in the programs "storage and crosslinked infrastructures" (SCI) and "science and technology of nanosystems" (STN). We also thank KIT's synchrotron radiation source (operated by KIT-IBPT) for ex situ XAS measurements conducted at the CAT-ACT beamline.

\section{References}

1 M. Bowker, R. Holroyd, A. Elliott, P. Morrall, A. Alouche, C. Entwistle and A. Toerncrona, The Selective Oxidation of Methanol to Formaldehyde on Iron Molybdate Catalysts and on Component Oxides, Catal. Lett., 2002, 83(3), 165-176.

2 M. P. House, A. F. Carley, R. Echeverria-Valda and M. Bowker, Effect of Varying the Cation Ratio within Iron Molybdate Catalysts for the Selective Oxidation of Methanol, J. Phys. Chem. C, 2008, 112(11), 4333-4341.

3 K. Routray, W. Zhou, C. J. Kiely, W. Grünert and I. E. Wachs, Origin of the synergistic interaction between $\mathrm{MoO}_{3}$ and iron molybdate for the selective oxidation of methanol to formaldehyde, J. Catal., 2010, 275(1), 84-98.

4 L. J. Burcham, L. E. Briand and I. E. Wachs, Quantification of Active Sites for the Determination of Methanol Oxidation Turn-over Frequencies Using Methanol Chemisorption and in Situ Infrared Techniques. 1. Supported Metal Oxide Catalysts, Langmuir, 2001, 17(20), 6164-6174.

5 A. P. V. Soares, M. F. Portela and A. Kiennemann, Methanol Selective Oxidation to Formaldehyde over Iron-Molybdate Catalysts, Catal. Rev., 2005, 47(1), 125-174.

6 M. P. House, A. F. Carley and M. Bowker, Selective oxidation of methanol on iron molybdate catalysts and the effects of surface reduction, J. Catal., 2007, 252(1), 88-96.

7 K. V. Raun, L. F. Lundegaard, J. Chevallier, P. Beato, C. C. Appel, K. Nielsen, M. Thorhauge, A. D. Jensen and M. Høj, Deactivation behavior of an iron-molybdate catalyst during selective oxidation of methanol to formaldehyde, Catal. Sci. Technol., 2018, 8(18), 4626-4637.

8 C. Brookes, P. P. Wells, N. Dimitratos, W. Jones, E. K. Gibson, D. J. Morgan, G. Cibin, C. Nicklin, D. Mora-Fonz, D. O. Scanlon, C. R. A. Catlow and M. Bowker, The Nature of the Molybdenum Surface in Iron Molybdate. The Active Phase in Selective Methanol Oxidation, J. Phys. Chem. C, 2014, 118(45), 26155-26161.

9 C. Brookes, M. Bowker, E. K. Gibson, D. Gianolio, K. M. H. Mohammed, S. Parry, S. M. Rogers, I. P. Silverwood and P. P. Wells, In situ spectroscopic investigations of MoOx/ $\mathrm{Fe}_{2} \mathrm{O}_{3}$ catalysts for the selective oxidation of methanol, Catal. Sci. Technol., 2016, 6(3), 722-730.

10 T. H. Kim, B. Ramachandra, J. S. Choi, M. B. Saidutta, K. Y. Choo, S.-D. Song and Y.-W. Rhee, Selective Oxidation of Methanol to Formaldehyde Using Modified IronMolybdate Catalysts, Catal. Lett., 2004, 98(2), 161-165.

11 M. Rellán-Piñeiro and N. López, The Active Molybdenum Oxide Phase in the Methanol Oxidation to Formaldehyde (Formox Process): A DFT Study, ChemSusChem, 2015, 8(13), 2231-2239.

12 E. M. McCarron III and A. W. Sleight, Oxy-Methoxy Compounds of Molybdenum (VI) and their Relationship to the Selective Oxidation of Methanol over Molybdate Catalysts, Polyhedron, 1986, 5, 129-139.

13 J. Ziolkowski, Advanced Bond-Strength Model of Active Sites on Oxide Catalysts, J. Catal., 1983, 84, 317-332.

14 R. K. Grasselli, Fundamental principles of selective heterogeneous oxidation catalysis, Top. Catal., 2002, 21, 79-88. 
15 W. E. Farneth, F. Ohuchi, R. H. Staley, U. Chowdry and A. W. Sleight, Mechanism of Partial Oxidation of Methanol Over $\mathrm{MoO}_{3}$ as Study by Temperature-Programmed Desorption, J. Phys. Chem., 1985, 89, 2493.

16 J. M. Tatibouët, Methanol oxidation as a catalytic surface probe, Appl. Catal., A, 1997, 148(2), 213-252.

17 M. G. O’Brien, A. M. Beale, S. D. M. Jacques and B. M. Weckhuysen, A Combined Multi-Technique In Situ Approach Used to Probe the Stability of Iron Molybdate Catalysts During Redox Cycling, Top. Catal., 2009, 52(10), 1400-1409.

18 S. D. M. Jacques, O. Leynaud, D. Strusevich, P. Stukas, P. Barnes, G. Sankar, M. Sheehy, M. G. O’Brien, A. Iglesias-Juez and A. M. Beale, Recent progress in the use of in situ X-ray methods for the study of heterogeneous catalysts in packed-bed capillary reactors, Catal. Today, 2009, 145(3), 204-212.

19 M. G. O’Brien, A. M. Beale, S. D. M. Jacques, M. Di Michiel and B. M. Weckhuysen, Closing the operando gap: The application of high energy photons for studying catalytic solids at work, Appl. Catal., A, 2011, 391(1), 468-476.

20 A. Gaur, M. Schumann, K. V. Raun, M. Stehle, P. Beato, A. D. Jensen, J. D. Grunwaldt and M. Hoj, Operando XAS/ XRD and Raman Spectroscopic Study of Structural Changes of the Iron Molybdate Catalyst during Selective Oxidation of Methanol, ChemCatChem, 2019, 11(19), 4871-4883.

21 W. van Beek, O. V. Safonova, G. Wiker and H. Emerich, SNBL, a dedicated beamline for combined in situ X-ray diffraction, X-ray absorption and Raman scattering experiments, Phase Transitions, 2011, 84(8), 726-732.

22 J.-D. Grunwaldt, N. v. Vegten and A. Baiker, Insight into the structure of supported palladium catalysts during the total oxidation of methane, Chem. Commun., 2007, (44), 4635-4637.
23 J.-D. Grunwaldt and B. S. Clausen, Combining XRD and EXAFS with on-Line Catalytic Studies for in situ Characterization of Catalysts, Top. Catal., 2002, 18(1), 37-43.

24 J. D. Grunwaldt, M. Caravati, S. Hannemann and A. Baiker, X-ray absorption spectroscopy under reaction conditions: suitability of different reaction cells for combined catalyst characterization and time-resolved studies, Phys. Chem. Chem. Phys., 2004, 6(11), 3037-3047.

25 B. Ravel and M. Newville, ATHENA, ARTEMIS, HEPHAESTUS: data analysis for X-ray absorption spectroscopy using IFEFFIT, J. Synchrotron Radiat., 2005, 12(4), 537-541.

26 A. M. Beale, S. D. M. Jacques, E. Sacaliuc-Parvalescu, M. G. O'Brien, P. Barnes and B. M. Weckhuysen, An iron molybdate catalyst for methanol to formaldehyde conversion prepared by a hydrothermal method and its characterization, Appl. Catal., A, 2009, 363(1), 143-152.

27 C. Brookes, P. P. Wells, G. Cibin, N. Dimitratos, W. Jones, D. J. Morgan and M. Bowker, Molybdenum Oxide on $\mathrm{Fe}_{2} \mathrm{O}_{3}$ Core-Shell Catalysts: Probing the Nature of the Structural Motifs Responsible for Methanol Oxidation Catalysis, ACS Catal., 2014, 4(1), 243-250.

28 M. Lv, W. Xie, S. Sun, G. Wu, L. Zheng, S. Chu, C. Gao and J. Bao, Activated-carbon-supported $\mathrm{K}-\mathrm{Co}-\mathrm{Mo}$ catalysts for synthesis of higher alcohols from syngas, Catal. Sci. Technol., 2015, 5(5), 2925-2934.

29 L.-b. Wu, L.-h. Wu, W.-m. Yang and A. I. Frenkel, Study of the local structure and oxidation state of iron in complex oxide catalysts for propylene ammoxidation, Catal. Sci. Technol., 2014, 4(8), 2512-2519.

30 A. Gaur and B. D. Shrivastava, Speciation using X-ray absorption fine structure (XAFS), Rev. J. Chem., 2015, 5(4), 361-398.

31 N. Pernicone, Deactivation of Fe-Mo oxide catalyst in industrial plant and simulation tests on laboratory scale, Catal. Today, 1991, 11(1), 85-91. 